\title{
Transmesocolic Hernia of the Ascending Colon with Intestinal Obstruction
}

\author{
Junji Ueda ${ }^{a}$ Hiroshi Yoshida $^{b}$ Hiroshi Makino $^{b}$ \\ Tadashi Yokoyama $^{\mathrm{b}}$ Hiroshi Maruyama $^{\mathrm{b}}$ Atsushi Hirakata $^{\mathrm{b}}$ \\ Hitomi Ueda $^{a}$ Manabu Watanabe $^{c}$ Eiichi Uchida $^{c}$ \\ Eiji Uchida ${ }^{a}$ \\ ${ }^{a}$ Department of Surgery, Nippon Medical School, 'bepartment of Surgery, \\ Nippon Medical School Tamanagayama Hospital, and ' Uchida Hospital, Tokyo, \\ Japan
}

\section{Key Words}

Transmesocolic hernia $\cdot$ Ascending colon $\cdot$ Intestinal obstruction

\begin{abstract}
An internal hernia may be either congenital or acquired. The reported incidence of such hernias is $1-2 \%$. In rare cases, internal hernias are the cause of small bowel obstruction, with a reported incidence of $0.2-0.9 \%$. Transmesocolic hernia of the ascending colon is especially rare. We report a case of transmesocolic hernia of the ascending colon with intestinal obstruction diagnosed preoperatively. A 91-year-old Japanese female was admitted to our hospital with abdominal distention and vomiting of 3 days duration. She had no past history of any abdominal surgery. Abdominal examination revealed distention and tenderness in the right iliac fossa. Abdominal computed tomography revealed ileus in the sac at the left side of the ascending colon and dilatation of the oral side of the intestine. We diagnosed a transmesocolic hernia of the ascending colon with intestinal obstruction and performed emergency surgery. At the time of operation, there was internal herniation of ileal loops through a defect in the ascending mesocolon, without any strangulation of the small bowel. The contents were reduced and the tear in the ascending mesocolon was closed. The postoperative course was uneventful and the patient was discharged 14 days after surgery. In conclusion, preoperative diagnosis of bowel obstruction caused by a congenital mesocolic hernia remains difficult despite the techniques currently available, so it is important to consider the possibility of a transmesocolic hernia when diagnosing a patient with ileus with no past history of abdominal surgery.
\end{abstract}




\section{Introduction}

Transmesocolic hernia is an extremely rare type of internal hernia [1]. The reported incidence of internal hernias ranges from 0.6 to $5.8 \%$ of all small bowel obstructions [2], and transmesocolic hernia accounts for approximately $5-10 \%$ of all internal hernias [3]. A transmesocolic hernia occurs when the intestine prolapses into an abnormal tear in the mesenterium [4]. Pathologic defects of the mesentery and visceral peritoneum are due mostly to congenital, surgical, traumatic, inflammatory or circulatory pathology. Congenital anomalies of intestinal rotation and peritoneal attachments are important predisposing factors that lead to internal herniation [5]. The classification is based on anatomic regions where internal hernias with distinctive clinical and radiographic features occur: paraduodenal (left > right) (53\%), foramen of Winslow (8\%), pericecal (13\%), intersigmoid (6\%), transmesenteric (8\%), transomental (1-4\%), retroanastomotic, supravesical and pelvic (6\%) [5]. Transmesocolic hernias are difficult to diagnose preoperatively and often require resection of the affected area of the intestine during surgery $[1,4,6]$. Transmesocolic hernias of the ascending colon are especially rare. We report a case of a transmesocolic hernia of the ascending colon with intestinal obstruction which was diagnosed preoperatively.

\section{Case Report}

A 91-year-old Japanese female was admitted to our hospital with abdominal distention and vomiting of 3 days duration. She had no past history of any abdominal surgery and her vital signs were stable. Abdominal examination revealed distention and tenderness in the right iliac fossa. Her bowel sounds were sluggish. Laboratory investigation on admission revealed a white blood

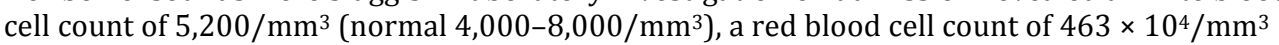
(normal 400-500 $\times 10^{4} / \mathrm{mm}^{3}$ ), a hemoglobin concentration of $13.5 \mathrm{~g} / \mathrm{dl}$ (normal 14-17 g/dl), a platelet count of $26.1 \times 10^{4} / \mathrm{mm}^{3}$ (normal $12-38 \times 10^{4} / \mathrm{mm}^{3}$ ) and a serum creatinine level of $0.9 \mathrm{mg} / \mathrm{dl}$ (normal $<0.2-1.0 \mathrm{mg} / \mathrm{dl}$ ). Tests on serum enzymes revealed an aspartate aminotransferase level of $32 \mathrm{IU} / \mathrm{l}$ (normal <31 IU/l), an alanine aminotransferase level of $24 \mathrm{IU} / \mathrm{l}$ (normal <31 IU/l), a $\gamma$-glutamyltransferase level of $15 \mathrm{IU} / \mathrm{l}$ (normal 8-45 IU/l) and C-reactive protein $2.7 \mathrm{mg} / \mathrm{ml}$ (normal $<0.3 \mathrm{mg} / \mathrm{dl}$ ). An abdominal X-ray showed multiple small bowel loops with air fluid levels with no free air under the dome of the diaphragm. Abdominal computed tomography (CT) revealed ileus in the sac at the left side of the ascending colon and dilatation of the oral side of the intestine (fig. 1). We diagnosed a transmesocolic hernia of the ascending colon with intestinal obstruction and performed emergency surgery.

At the time of the operation, there was internal herniation of ileal loops through a defect in the ascending mesocolon, without any strangulation of the small bowel. The contents were reduced and the tear in the ascending mesocolon was closed (fig. 2 ). The postoperative course was uneventful and the patient was discharged on postoperative day 14. She was followed up as an outpatient for 3 months and had no further difficulties.

\section{Discussion}

An internal hernia is defined as the protrusion of a viscus through a normal or abnormal opening within the confines of the abdominal cavity [7]. These hernias may be either congenital or acquired. The herniation may be persistent. In the literature there are few cases of mesocolic hernia [8]. The anomaly of transmesocolic herniation, which was first reported by Rokitansky in 1836, is an extremely rare type of internal 
hernia [2]. Approximately 5-10\% of all internal hernias occur through defects in the mesentery of the small bowel; almost $35 \%$ of transmesocolic hernias are observed among pediatric patients, mainly those aged between 3 and 10 years [5].

Following the embryonic formation of an intestinal loop, congenital defects occur in areas of the mesentery that are thin and avascular, such as in the mesenteries of the lower ileum, the sigmoid mesocolon and the transverse mesocolon. Thus, a number of theories on the congenital causes of mesenteric tears have been proposed [9]. An etiologic relationship with prenatal intestinal ischemic accidents seems likely because such mesenteric apertures and associated hernias are found frequently in infants with atretic bowel segments [6]. In adults, however, most mesenteric defects are the result of previous gastrointestinal operations, abdominal trauma or intraperitoneal inflammation $[6,10,11]$. Our case was a rare presentation in an adult without a history of trauma or previous surgery.

A transmesocolic hernia is difficult to diagnose preoperatively and often requires resection of the affected intestine during surgery $[2,6]$. While some patients with internal hernias are asymptomatic, others have nonspecific symptoms such as chronic dyspepsia, intermittent colicky abdominal pain and vomiting. The rare occurrence of internal hernias (5.8\% of all small bowel obstructions) [12] and the absence of specific clinical features make a clinical diagnosis difficult [8].

It has been reported that the diagnosis of mesocolic hernia includes the following: (1) sacculation and crowding together of loops of small bowel contained in the hernial sac (fluoroscopy and serial radiographs are crucial in revealing that these loops cannot be separated by manipulation or a change in position, but rather move in toto); (2) disturbed arrangement and abnormal location of the small intestine [5]. Valid support may be provided by a CT scan, which can demonstrate encapsulated clusters of small intestinal loops in the hernial sac and the anterior and upward displacement of the inferior mesenteric vein [13-15]. However, clinical and radiologic differentiation of mesenteric hernia from other closed-loop obstructions may be impossible [5]. In our case, abdominal CT revealed typical findings in which ileus in the sac was detected at the left side of the ascending colon. We were able to preoperatively diagnose a transmesocolic hernia of the ascending colon.

Transmesocolic hernia of the ascending colon is very rare. Intestinal mesenteric hernias account for $70 \%$ of all transmesocolic hernias. Hernias of the transverse colon account for $60 \%$ of all other transmesocolic hernias. There are no reports of transmesocolic hernias of the ascending colon in the PubMed search engine, and there are only two reports of this in Japan. These cases are summarized in table 1. Our case was the only one that could be diagnosed preoperatively.

\section{Conclusion}

In this case, we encountered a transmesocolic hernia of the ascending colon with intestinal obstruction which was diagnosed preoperatively. Preoperative diagnosis of bowel obstructions caused by a congenital mesocolic hernia remains difficult despite the techniques currently available, so it is important to consider the possibility of a 


\begin{tabular}{r|l|l|l}
$\begin{array}{r}\text { Case Reports in } \\
\text { Gastroenterology }\end{array}$ & $\begin{array}{l}\text { Case Rep Gastroenterol 2012;6:344-349 } \\
\text { DOI: 10.1159/000339691 }\end{array}$ & $\begin{array}{l}\text { Published online: } \\
\text { June 7, 2012 }\end{array}$ & $\begin{array}{l}\text { @ 2012 S. Karger AG, Basel } \\
\text { ISSN 1662-0631 } \\
\text { www.karger.com/crg }\end{array}$ \\
\hline
\end{tabular}

transmesocolic hernia when we diagnose a patient with ileus with no past history of abdominal surgery.

\section{Disclosure Statement}

The authors declare that they have no competing interests.

Table 1. Reports of transmesocolic hernia of the ascending colon

\begin{tabular}{lllllll}
\hline $\begin{array}{l}\text { Refer- } \\
\text { ence }\end{array}$ & $\begin{array}{l}\text { Age, } \\
\text { years }\end{array}$ & Sex & Chief complaint & CT findings & $\begin{array}{l}\text { Preoperative } \\
\text { diagnosis }\end{array}$ & Operation \\
\hline 16 & 91 & female & abdominal pain & $\begin{array}{l}\text { dilatation of jejunum, niveau and tumor-like } \\
\text { lesion in the right lower abdominal cavity }\end{array}$ & $\begin{array}{l}\text { Out- } \\
\text { come }\end{array}$ \\
\hline 17 & 80 & male & $\begin{array}{l}\text { right lower } \\
\text { quadrant pain }\end{array}$ & $\begin{array}{l}\text { dilatation of the intestine } \\
\text { of the defect }\end{array}$ & internal hernia & $\begin{array}{l}\text { primary closure } \\
\text { of the defect }\end{array}$ \\
\hline $\begin{array}{l}\text { Our } \\
\text { case }\end{array}$ & 91 & female & $\begin{array}{l}\text { abdominal } \\
\text { distention, } \\
\text { vomiting }\end{array}$ & $\begin{array}{l}\text { ileum in the sac at the left side of the } \\
\text { ascending colon and dilatation of the oral } \\
\text { side of the intestine }\end{array}$ & $\begin{array}{l}\text { mesocolic hernia of } \\
\text { the ascending colon }\end{array}$ & $\begin{array}{l}\text { primary closure } \\
\text { of the defect }\end{array}$ \\
\hline
\end{tabular}

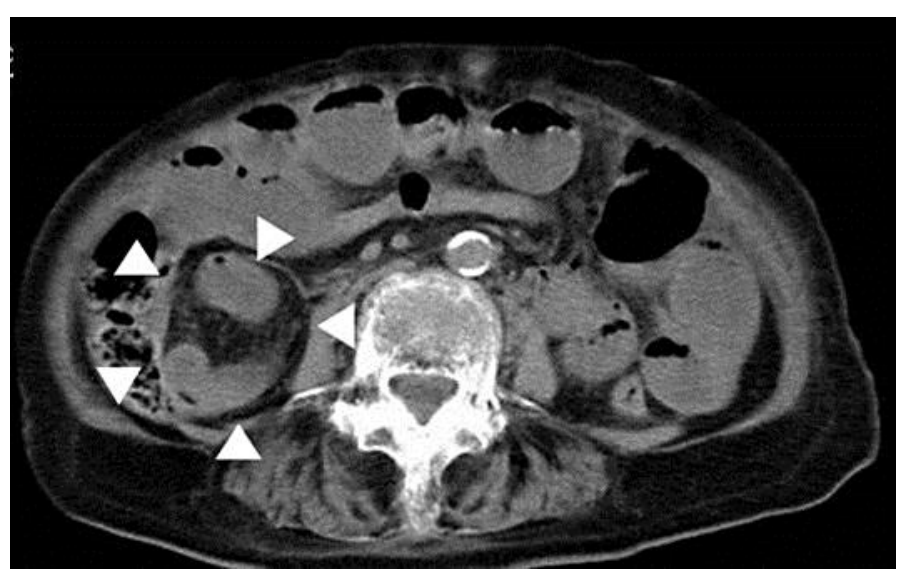

Fig. 1. Abdominal CT revealed ileus in the sac at the left side of the ascending colon (arrowheads) and dilatation of the oral side of the intestine. 

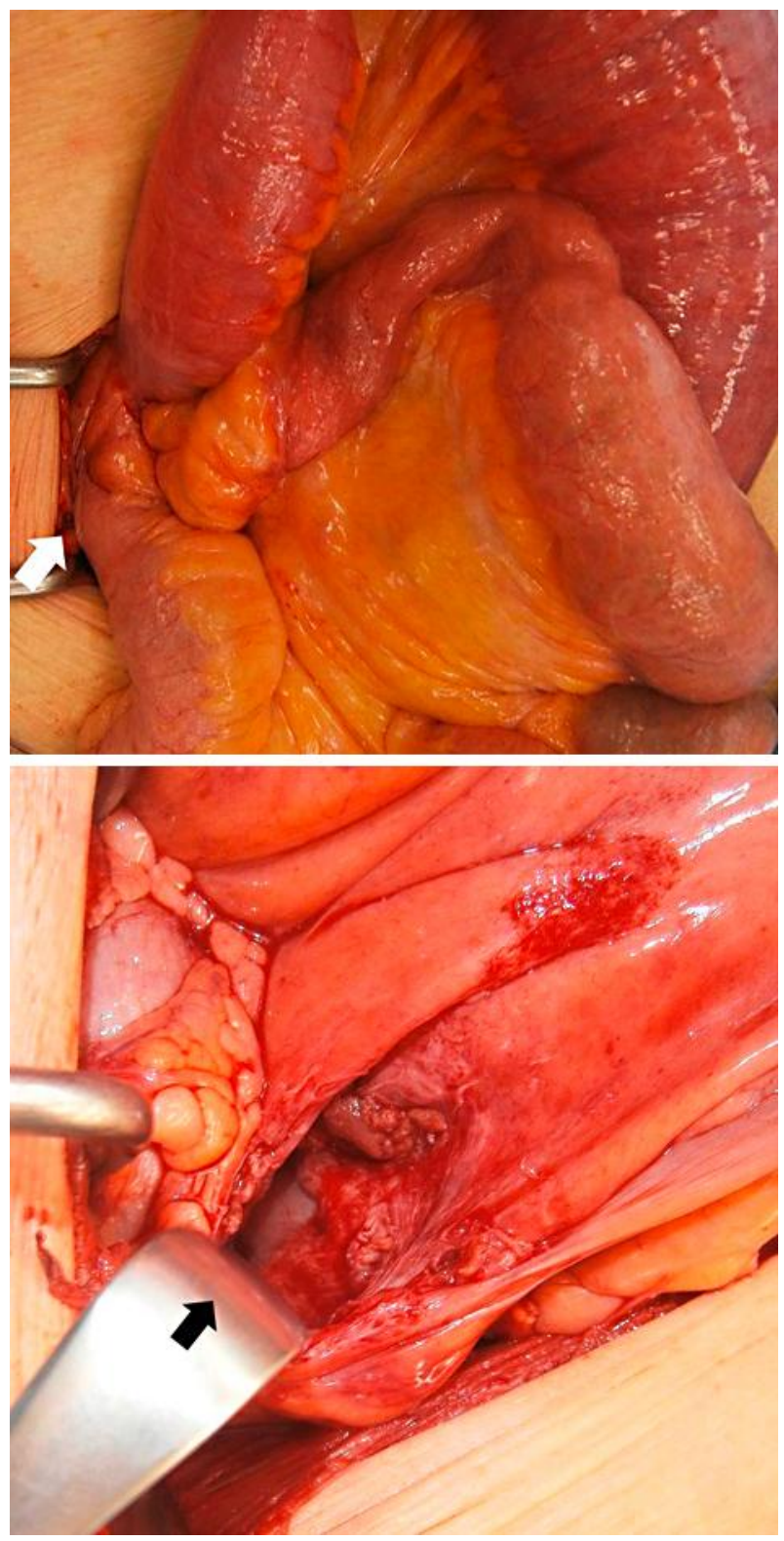

Fig. 2. At the time of surgery, there was internal herniation of ileal loops through a defect in the ascending mesocolon (white arrow), without any strangulation of the small bowel. The contents were reduced (black arrow) and the tear in the ascending mesocolon was closed.

\section{References}

1 Kuga T, Taniguchi S, Inoue T, Zempo N, Esato K: The occurrence of a strangulated ileus due to a traumatic transmesenteric hernia: report of a case. Surg Today 2000;30:548-550.

-2 Newsom BD, Kukora JS: Congenital and acquired internal hernias: unusual causes of small bowel obstruction. Am J Surg 1986;152:279-285.

-3 Agresta F, Mazzarolo G, Bedin N: Incarcerated internal hernia of the small int estine through a re-approximated peritoneum after a trans-abdominal pre-peritoneal procedure - apropos of two cases: review of the literature. Hernia 2011;15:347-350. 
-4 Janin Y, Stone AM, Wise L: Mesenteric hernia. Surg Gynecol Obstet 1980;150:747-754.

5 Gomes R, Rodrigues J: Spontaneous adult transmesenteric hernia with bowel gangrene. Hernia 2011;15:343-345

6 Murphy DA: Internal hernias in infancy and childhood. Surgery 1964;55:311-316.

7 Uchiyama S, Imamura N, Hidaka H, Maehara N, Nagaike K, Ikenaga N, Hotokezaka M, Chijiiwa K: An unusual variant of a left paraduodenal hernia diagnosed and treated by laparoscopic surgery: report of a case. Surg Today 2009;39:533-535.

8 Frediani S, Almberger M, Iaconelli R, Avventurieri G, Manganaro F: An unusual case of congenital mesocolic hernia. Hernia 2010;14:105-107.

-9 Treves F: Lectures on the anatomy of the intestinal canal and peritoneum in man. Br Med J 1885;1: 470-474.

10 Shaffner Lde S, Pennell TC: Congenital internal hernia. Surg Clin North Am 1971;51:1355-1359.

11 Mock CJ, Mock HE Jr: Strangulated internal hernia associated with trauma. AMA Arch Surg 1958;77: 881-886.

12 Martin LC, Merkle EM, Thompson WM: Review of internal hernias: radiographic and clinical findings. AJR Am J Roentgenol 2006;186:703-717.

13 Suchato C, Pekanan P, Panjapiyakul C: CT findings in symptomatic left paraduodenal hernia. Abdom Imaging 1996;21:148-149.

14 Schaffler GJ, Groell R, Kammerhuber F, Stacher R, Hammerl R, Rabl H, Hoess G, Szolar DH: Anterior and upward displacement of the inferior mesenteric vein: a new diagnostic clue to left paraduodenal hernias? Abdom Imaging 1999;24:29-31.

15 Mathieu D, Luciani A: Internal abdominal herniations. AJR Am J Roentgenol 2004;183:397-404.

16 Ishizaki Y, Nakatsuka H, Matsugu Y, Toyota K: A case of mesenteric hiatal hernia of the ascending mesocolon (in Japanese). J Jpn Surg Assoc 2000;61:1900-1903.

17 Tsukuda K, Furutani S, Takagi S, Ikeda E, Hirai R, Tsuji H: A case of transmesocolic hernia of ascending colon (in Japanese). J Jpn Surg Assoc 2006;67:1926-1928. 